\title{
El aprendiz de rapsodo, o de cuando Homero cruzó la laguna Estigia (Lucianus, Cont. 7)*
}

\author{
Pilar Gómez Cardó \\ Universidad de Barcelona \\ pgomez@ub.edu
The rhapsodist's apprentice, or when Homer crossed the Styx (Lucianus, Cont. 7)

En Caronte o los observadores el barquero del inframundo conversa, en la tierra, con el dios Hermes sobre la riqueza, la felicidad y el vano afán humano por los bienes materiales. Por ello esta obra ha sido considerada una muestra de sátira menipea en el corpus lucianeo.

Por otra parte, la poesía homérica actúa en esta pieza como permanente telón de fondo. Luciano se sirve de versos homéricos, o mejor dicho, de versos a la manera homérica, para censurar el mundo mortal; $\mathrm{y}$, además, pone esos versos en boca de un personaje que, para practicar el arte de la rapsodia, debe renunciar por un tiempo a su oficio de barquero.

Este trabajo analiza un problema textual, puesto que la tradición manuscrita en Cont. 7 ofrece dos variantes para referirse al canto de Homero. En un contexto donde la intención de Luciano es no sólo burlarse de los necios mortales, sino incluso del poeta griego por excelencia, la lectura de los ueteres es más acertada porque ésta ilustra mejor el efecto y la intención paródica de Luciano al recordar a Homero, intentando adecuar forma y contenido al amparo de la tradición griega.

Palabras clave: Luciano; Caronte; Homero; rapsodo; poesía homérica; parodia.
In Charon or the Inspectors we find the ferryman of the underworld on earth, talking to the god Hermes about wealth, happiness, and the vain human striving for material goods. The piece has been considered to be an example of Menippean satire inside the corpus of Lucian's works.

Homeric poetry is always in the background. Lucian uses Homeric verses, or rather, verses structured in the Homeric manner, to formulate his critical view of the mortal world; in addition, he puts these verses into the mouth of a character who must temporarily give up his job as a ferryman in order to practise the art of rhapsody.

This paper analyses a textual problem: the two variants in Cont. 7 referring to Homer in the manuscript tradition. In a context in which Lucian wants to make fun not just of foolish humans but also of the Greek poet par excellence, the reading of the ueteres seems more appropriate because it illustrates better Lucian's parodic intention in recalling Homer and in trying to adapt form and content to the Greek tradition.

Keywords: Lucian; Charon; Homer; rhapsodist; Homeric poetry; parody.

* Este trabajo ha sido realizado en el marco del proyecto «Recrear el logos: narrativas griegas de época imperial» (FFI2009-08858), dirigido por la Dra. Francesca Mestre y financiado por el Ministerio de Ciencia e Innovación. 
La figura de Caronte, dado el interés de Luciano por el inframundo, aparece en varias de sus obras, aunque el barquero suele desempeñar un papel secundario, ya que o bien se alude a él como un simple tópico relacionado con la muerte ${ }^{1}$, o bien se limita a ejercer su oficio preocupándose sólo por sus ganancias², De modo que sus palabras inciden poco en el contenido de la obra y contribuyen sólo al desarrollo dramático. Sin embargo, protagoniza la pieza Caronte o los observadores cuya acción - paradojas de Luciano - no se desarrolla en el Hades.

El diálogo entre Caronte y Hermes se identifica como una de las más significativas muestras de sátira menipea del corpus lucianeo por la visión negativa y crítica de la actitud vital genérica de los humanos que este texto contiene. Por otra parte, es, sin duda, innegable la proximidad de esta obra con otras como Icaromenipo o el que vuela por encima de la nube, Descenso hacia el Hades o el tirano y Menipo o la necromancia, bien sea por el papel paralelo que en ellas desempeñan Caronte, Menipo o Cinisco, bien sea por el escenario de observatorio que Luciano construye para sus protagonistas ${ }^{3}$, bien sea también por la visita que éstos realizan a espacios que no son los suyos habituales.

No obstante, antes de etiquetar las obras de Luciano desde el punto de vista ideológico, hay que tener en cuenta siempre su eclecticismo, o por lo menos su capacidad para conjugar distintas concepciones filosóficas, máxime cuando el objetivo primordial de sus obras no es testificar su propia filiación a una u otra escuela de pensamiento, sino ante todo poner en duda el comportamiento vacuo, fingido, antinatural incluso, del género humano, sin que ello signifique necesariamente la adscripción del samosatense a una doctrina concreta, aunque sí puedan reconocérsele ideas u orientaciones de un determinado signo ${ }^{4}$. Así — como señala Bompaire ${ }^{5}$ - Caronte o los observadores es un diálogo de evidente coloración cínica y, en consecuencia, no debe causar extrañeza que Luciano incluya en él diversos tópicos propios de la diatri$\mathrm{ba}^{6}$; unos lugares comunes que igualmente aparecen en otras obras del samosatense no por ello calificadas de menipeas.

Además es necesario valorar también, al analizar los textos de Luciano, la forma literaria empleada, pues ésta puede ser indicio del propósito de Lucia-

\footnotetext{
${ }^{1}$ Luc., Demon. 45; Nec. 10; Philops. 25.

2 Luc., Cat. 21; DMort. II, XIV.

${ }^{3}$ Cf. Camerotto 1998, pp. 234-242.

${ }^{4}$ Cf. Bonazzi 2010, pp. 37-41; Decharneux 2010, p. 64.

5 Bompaire 1958, p. 55; 2008, p. 4.

${ }^{6}$ Cf. Nesselrath 1998, p. 135.
} 
no al tratar un contenido, de modo que no siempre resulta fácil deslindar si la intención satírica, burlesca e incluso paródica presente en sus escritos, afecta a los temas elegidos o a la forma en que son tratados, o a ambos.

Así, en Caronte o los observadores la poesía homérica actúa como permanente telón de fondo de toda la pieza. Pero si Homero fue siempre escue$1 a^{7}$, y si la poesía homérica sirvió para explicar la vida de dioses y héroes, ofreciendo a través de sus versos una determinada concepción del mundo, Luciano aprovecha todavía al poeta de Quíos ${ }^{8}$ para mostrar en esta obra también él una determinada interpretación de la existencia humana. Luciano se sirve de versos homéricos, o mejor dicho, de versos a la manera homérica para formular precisamente una visión negativa y crítica del mundo mortal; $\mathrm{y}$, además, los pone en boca de un personaje que, para practicar el arte de la rapsodia, debe renunciar por un tiempo a su oficio de barquero. De este modo, aún resulta más evidente el efecto y la intención paródica de Luciano, al burlarse así no sólo de los necios mortales, sino también del poeta por excelencia de su propia tradición literaria.

El Caronte de Luciano se presenta en forma de diálogo entre el dios Hermes y Caronte, quien abandona el mundo subterráneo con la intención de conocer de primera mano qué sucede en la tierra y cómo viven en ella los hombres con el fin de lograr entender por qué se muestran tan reacios a abandonarla; es decir, quiere saber, para contar él mismo su propia iotopía sobre ellos.

La acción de esta obra transcurre en la tierra y se sitúa en dos planos claramente diferenciados. Caronte y Hermes no se mezclan con los hombres, objeto de su atención, sino que optan por observarlos - de ahí el subtítulo de

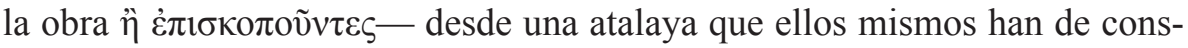
truirse. El segundo plano corresponde a los hombres y presenta diversos escenarios espaciales — griegos y bárbaros - y temporales — nunca posteriores al siglo $\mathrm{V}$ a. C. ${ }^{9}$ - , cuya descripción constituye la parte esencial del diálogo

7 El interés por Homero fue, desde diversas perspectivas, una constante entre los autores de la Segunda Sofística, para quienes el poeta épico seguía siendo voz de autoridad; cf. Kindstrand 1973, pp. 99-110; Mestre 2004, pp. 138-139; Gómez y Mestre 2006, pp. 355-361; Díaz Lavado 2010.

${ }^{8}$ Homero, no obstante, después de muerto, en la Isla de los Bienaventurados, al saber que su patria es objeto de disputa entre los mortales, desmiente su origen griego, se confiesa originario de Babilonia y revela su verdadero nombre: Tigranes (Luc., VH II 20).

${ }^{9}$ La cronología de la referencia a hechos históricos es un parámetro utilizado por Helm 1906, pp. 56-61, para reivindicar la filiación menipea de las obras de Luciano. Este argumento es, sin embargo, rebatido por Hall 1981, pp. 82-94. 
mismo entre Caronte y Hermes. Este diálogo sirve, a la vez, de marco a otro diálogo que es posible seguir en directo - es decir, no es referido en la conversación entre el dios y el barquero-; se trata del que mantuvieron Creso y Solón, cuando el sabio ateniense visitaba la corte de Sardes, de acuerdo con la noticia transmitida por Herodoto (III 39-43). La finalidad de este segundo diálogo es ilustrar uno de los temas en torno a los cuales gira la inicial charla de Caronte y Hermes: el vano afán de los mortales por asociar la felicidad con bienes materiales.

¿Qué es lo que se propone averiguar Caronte, en realidad? En primer lugar, Caronte quiere saber y ese saber es identificado, de entrada, con un espacio de luz frente a las sombras eternas en que transcurre su existencia. Hermes reconoce la necesaria liberación de Caronte para alcanzar un pleno conocimiento, ya que éste sólo será posible al salir de la oscuridad infernal, donde, a modo de caverna, el barquero hasta entonces sólo ha sido capaz de intuir imágenes de la realidad terrenal ${ }^{10}$; hasta él sólo llegan espectros y, por lo tanto, únicamente a través de esas sombras ha podido imaginarse la vida de los hombres cuya efectiva existencia todos sus pasajeros, salvo algunas significativas excepciones ${ }^{11}$, suspiran por recuperar.

Si el desarrollo de la obra se construye sobre la interacción de dos planos, el aéreo ${ }^{12}$ y el terrenal, no menos determinante es también - a nuestro juicio - la interacción que en su desarrollo se produce entre el nivel formal y el de contenido.

Construir un mirador para contemplar requiere una técnica determinada, es una tarea propia de arquitectos, a la que se aplican Hermes y Caronte; pero, para acometer dicha empresa, Hermes acude al mito y a la poesía homérica como guías infalibles de su objetivo. No en vano Homero mismo es califica-

10 Una reminiscencia, sin duda, del mito de la caverna, utilizado por Platón, precisamente, para explicar de forma alegórica la situación de ceguera en la que se encuentra el hombre respecto al conocimiento; cf. Pl., R. 508c-516d.

11 Así, p. ej., Cinisco (Luc., Cat. 7), Micilo (ibíd. 14, 16), Menipo (DMort. II-X) o Diógenes (ibíd. XIII, XVI).

12 La imagen de la observación desde lo alto recurre en otras obras de Luciano. Además de la fantástica aventura de Menipo llegando hasta el cielo convertido en un doble del mítico Ícaro en Icaromenipo, Luciano cuenta su propia experiencia de observador aéreo en el Sueño $o$ vida de Luciano 15-17, cuando el paseo en el carro alado de Paideia le permite también conocer, después de haber abandonado su aprendizaje como escultor; Gómez 1994, p. 209; Brandão 2001, pp. 203-227; Camerotto 2009, pp. 41-47. 
do de $\alpha \rho \chi \imath \varepsilon \dot{\varepsilon} \kappa \tau \omega v^{13}$ (Cont. 4) y será el maestro de obras, ya que son sus palabras las que inspiran y orientan la construcción del observatorio desde donde Caronte y Hermes examinan la existencia humana.

En efecto, cuando ambos se plantean qué altura puede ser la más adecuada para ese examen, el dios propone seguir las indicaciones del poeta, tomando como ejemplo el proceder de Oto y Efialtes al intentar tener un acceso fácil al cielo para atacar a los dioses. Para ello, los jóvenes — quienes «con nueve años tenían nueve codos de ancho y nueve brazas de estatura» (Od. XI 311-312) - arrancaron de raíz el monte Osa y lo colocaron sobre el Olimpo, aunque fueron debidamente castigados por insolentes antes de alcanzar su objetivo. No obstante, Hermes y Caronte, conscientes de que su intención no es ahora hostil hacia el Olimpo, se atreven a imitar a los jóvenes gigantes, al tiempo que Luciano reconoce cuán útil puede resultar para su edificación —una construcción de palabras - 'plagiar' al bueno ( $\gamma \varepsilon v v \alpha ́ \delta \alpha \varsigma)$ de Homero, quien en sólo dos versos es capaz de poner con facilidad unas montañas sobre otras $^{14}$. Caronte, por ser — según Hermes - «muy poco dado a la poesía»

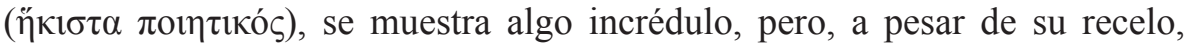
colabora en la tarea, y el dios puede así evocar las propias palabras de Homero cuando dan por finalizada, de forma fácil y poética ${ }^{15}$, su obra, que ha consistido en colocar «encima del Osa el frondoso Pelio» (Cont. 4).

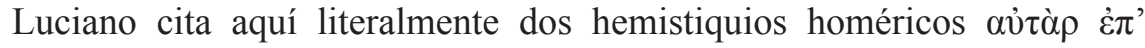

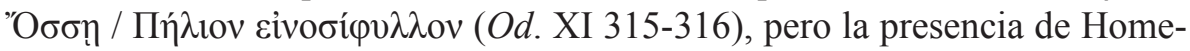
ro en el Caronte reviste distintas modalidades: la mera alusión al poeta, la cita directa, las referencias a temas homéricos, la paráfrasis de versos, la adaptación de éstos o el puro centón ${ }^{16}$. Asimismo, tanto la Ilíada como la Odisea se encuentran representadas por igual y, en cuanto a los héroes homé-

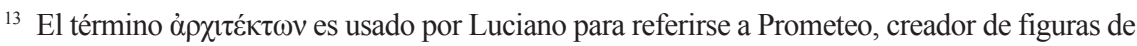

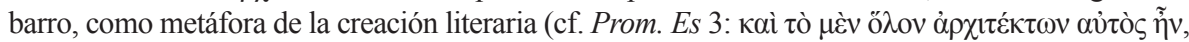

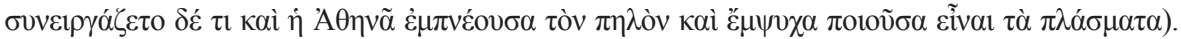

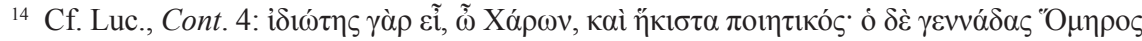

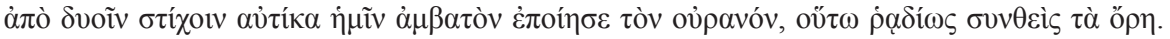

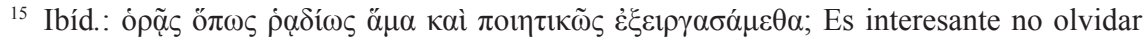
aquí el significado originario del verbo $\pi$ oté $\omega$ 'hacer, fabricar, producir' (cf. Chantraine 1974, p. 922) para observar cómo resulta difícil en este contexto la traducción del adverbio

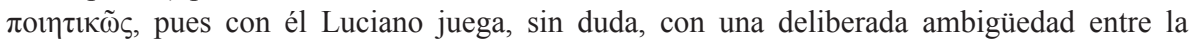
construcción física de la atalaya y su elaboración mediante palabras.

${ }^{16}$ Cf. Branham 1989, p. 140: «No other author is drawn on as frequently or in as many different ways». 
ricos, son explícitamente mencionados Áyax y Aquiles y se alude de forma directa sin nombrarlo a Protesilao, «aquel joven tesalio» (§1), con el que se equipara Caronte al haber podido también él escapar por unas horas de las tinieblas infernales ${ }^{17}$.

Las distintas formas de esa presencia homérica no son, sin embargo, utilizadas al azar por Luciano ni de manera arbitraria por uno u otro de los personajes; por ejemplo, Homero no aparece nunca en el diálogo entre Creso y Solón. Además, Homero es usado también para definir una cierta rivalidad verbal entre Hermes y Caronte.

$\mathrm{Si}$ en el proceso de construir la atalaya de observación es Hermes quien se hace eco de la poesía épica, tampoco Caronte deja pasar ninguna oportunidad para demostrar su aptitud comunicativa y expresiva, que equivale a exhibir un buen conocimiento de la tradición literaria - como correspondería a cualquier erudito coetáneo de Luciano-, concretada, en este caso, en la poesía homérica.

Así, una vez ya instalados en el mirador, y para mejorar la agudeza visual del barquero, Hermes cita todavía dos versos de Homero ${ }^{18}$, que pertenecen ahora al pasaje de la Ilíada (V 127-128) en que Atenea aconseja a Diomedes no luchar con ningún dios, salvo con Afrodita: 'A $\chi \lambda \hat{\nu} v \delta$ ' $\alpha \tilde{v} \tau o \mathrm{\alpha} \alpha \pi^{\prime}$ 'ỏ $\varphi \theta \alpha \lambda \mu \tilde{\omega} v$

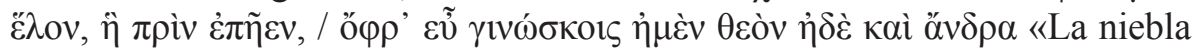
que antes los cubría he apartado de tus ojos, a fin de que conozcas bien si es un dios o un hombre» (Cont. 7) ${ }^{19}$. Entonces, Caronte - brioso como Diomedes $^{20}$ - desafía al dios diciéndole que puede ser tan homérico como él en su interrogatorio, y de este modo sienta una base literaria, al menos desde el punto de vista formal, sobre la que se desarrollará su conversación: $\grave{\alpha} \lambda \lambda \dot{\alpha}$

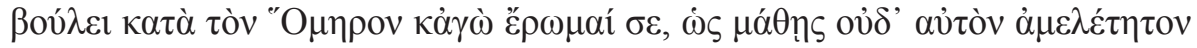

${ }^{17}$ En el Heroico de Filóstrato, el bello Protesilao, redivivo en Tracia, es quien sustenta con su ayuda y protección la feliz existencia del viñador a través de cuyas palabras, inspiradas también por Protesilao, el comerciante fenicio conoce cómo son los héroes y qué sucedió en Troya.

18 Sobre el empleo de versos homéricos en curaciones, cf. Gil 2004, pp. 215-240.

19 Se trata, en este caso, de un cita homérica literal que presenta una variante textual en la

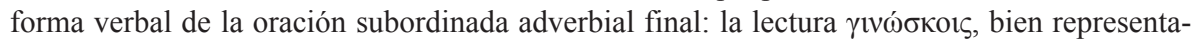
da en la tradición manuscrita de Luciano, y adoptada por los editores modernos (Jacobitz,

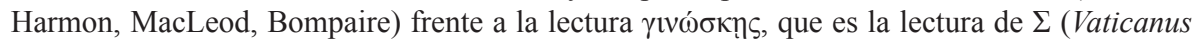
Graecus 224, s. XIV, considerado mixto) y de la mayor parte de códices homéricos, adoptada por los editores de Luciano más antiguos.

${ }^{20}$ Cf. Hom., Il. V 134-165. 


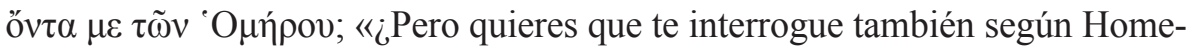
ro, para que sepas que yo mismo no soy inexperto en sus versos?» (Cont. 7). Hermes parece algo desconcertado ante la provocación literaria de Caronte y cuestiona cómo un mero barquero puede expresarse de forma erudita, es decir, cómo, amén de manejar con arte el remo, es capaz de hablar poética-

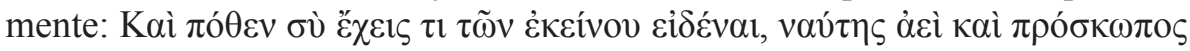
ڤैv; (Cont. 7) ${ }^{21}$. Es posible - justifica Caronte en su respuesta - por haber aprendido versos de boca del propio Homero, quien transitó la Estigia sin dejar de recitar; quizás, como sea propio de un poeta, pero con tanta destreza como poco acierto en la elección del tema $-\mathrm{y}$ aquí Luciano añade su pizca de humor-, ya que sus versos se hicieron realidad: las nubes amontonadas por Poseidón y el mar agitado por su tridente ${ }^{22}$ alteraron hasta tal punto la

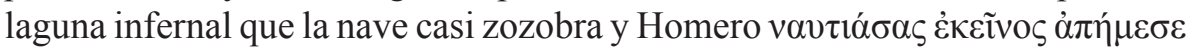

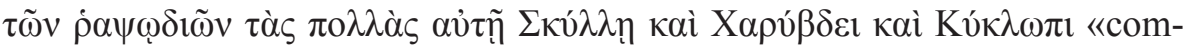
pletamente mareado, empezó a vomitar buena parte de sus cantos, incluidos los de Escila, Caribdis y el Cíclope» (Cont. 7$)^{23}$.

Sin embargo, Luciano no inventa esa metáfora del vómito de palabras,

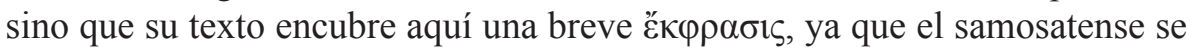
hace eco de una imagen consagrada por la tradición plástica: el pintor helenístico Galatón había pintado a Homero vomitando versos y al resto de poetas recogiendo el vómito ${ }^{24}$.

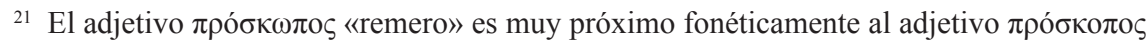
«que se anticipa en la observación»; quizás por esa similitud — habida cuenta de la importancia semántica de los términos relacionados con la observación y la visión en esta obraLuciano lo usa aquí dos veces, una frecuencia muy alta dado el escaso uso del término en el conjunto de los textos griegos, y él mismo sólo utiliza $\pi \rho$ ó $\kappa \omega \pi$ o hacia el Hades o el tirano (Cat. 19). Sin duda, esa ambigüedad de significado, por razones estrictamente fonéticas, en el contexto de Caronte o los observadores se realza si se piensa en una posible escenificación del diálogo; cf. Mestre (e. p.).

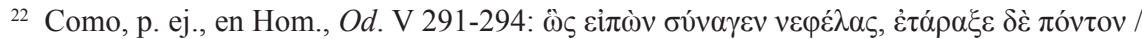

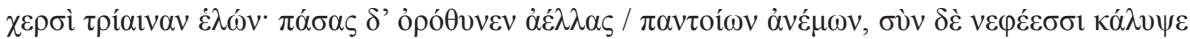

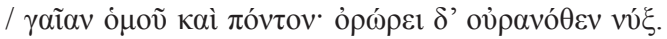

${ }^{23}$ Entre los cantos vomitados por Homero, Luciano menciona de forma explícita los relativos a Escila, Caribdis y el Cíclope no sólo porque se trata de pasajes bien conocidos, sino probablemente también porque describen agitación de las aguas; cf. Hom., Od. IX 536542; XII 403-453.

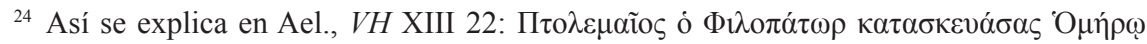

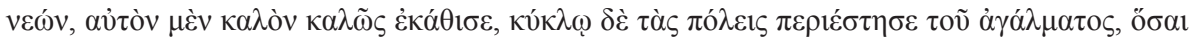


El pasaje de Caronte o los observadores que describe el recitado de Homero presenta un problema textual, que quizás no sea irrelevante al explorar la raíz homérica de esta obra y el propósito de Luciano. La tradición manus-

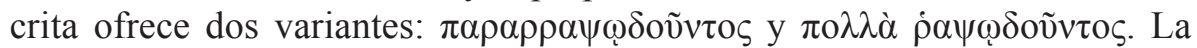

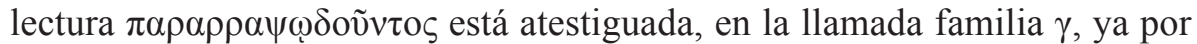
los ueteres $\Gamma$ (Vaticanus Graecus 90, s. X) y $\Omega$ (Marcianus Graecus 840; olim 434, s. X/XI), y los más recientes Ca (Cantabrigensis, Add. 2603, s. XIII/XIV), I (Urbinas Graecus 118, s. XIII/XIV), M (Parisinus Graecus 2954, olim Florentinus, s. XIV) y B (Palatinus Graecus 174, s. XIV), así como por el manuscrito C (Parisinus Graecus 3011, s. XIV), que suele con-

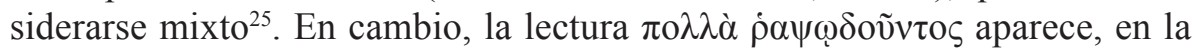
conocida como familia $\beta$, en los manuscritos B (Vindobonensis Phil. Graecus 123 , s. XI) y P (Vaticanus Graecus 76, s. XIV), y en los mixtos $\Sigma$ (Vaticanus Graecus 224, s. XIV), A (Gorlicensis Milichianus II, 12, s. XV) y N (Vaticanus Graecus 2957, s. XV). Esta última lectura, que también se encuentra en la tradición $\gamma$ (en $\Omega^{\mathrm{mg}} \mathrm{M}^{2 \mathrm{mg}}$ ), ha sido unánimemente adoptada por los editores ${ }^{26}$, incluso por quienes consideran mejor esa tradición llamada $\gamma$ (Harmon y Macleod, por ejemplo), que se apoya en el manuscrito $\Gamma$, puesto que éste estaría muy próximo al arquetipo y a pesar de que $\mathrm{M}$ ante correctionem posiblemente sirvió de modelo para la editio princeps de Florencia (1496), influyendo en la vulgata ${ }^{27}$.

La preferencia de los editores por mantener en el texto de Luciano una

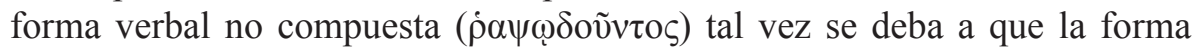

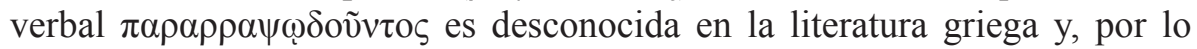
tanto, constituiría un hapax de Luciano. No obstante, encontrar hapax en el corpus lucianeo no es extraño, dada la habilidad del samosatense para la construcción de neologismos y para un uso ágil y dinámico de la lengua

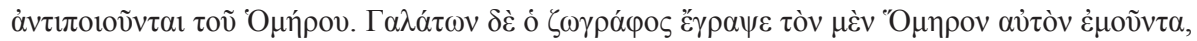

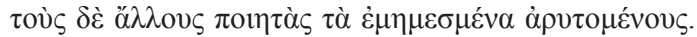

${ }^{25}$ Cf. Macleod 1972, p. XVIII; Jufresa, Mestre y Gómez 2000, p. XXVI. Bompaire 1993, pp. CVIII-CIX, analiza el manuscrito $C$ entre los de la $\beta$, al igual que Jacobitz, quien lo valora favorablemente en su editio maior (Jacobitz 1836, pp. XXIII-XXIV), considerándolo el mejor de los manuscritos parisinos.

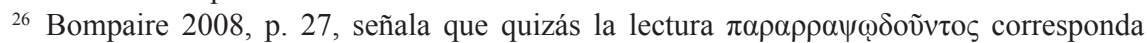
también a la traducción parisina de Belin de Ballu (1788-1789). Sin embargo, esta lectura no es incorporada en la editio bipontina; cf. Hemsterhuys y Reitz 1790, p. 40.

${ }^{27}$ Cf. Bompaire 1993, p. XCIV. 
griega en genera ${ }^{28}$. En cambio, quizás, el valor que puede dar a la forma

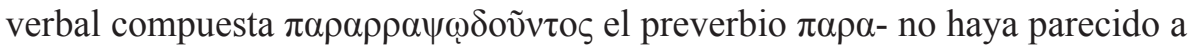
los editores demasiado adecuado para determinar al substantivo de referencia que es, precisamente, Homero, si se considera sólo el significado de 'junto a', 'al lado de' —y, por extensión, la idea de 'marginal' o 'a la contra'-, que aporta el preverbio: ¿cómo podría el excelso Homero no ser un aedo, sino dedicarse sólo a hilvanar versos y, además, hacerlo de un modo inapropiado, incluso 'parodiándose/contrarrecitándose' a sí mismo?

Sin embargo, en los verbos compuestos con preposición a menudo el primer elemento no determina al segundo, sino que sirve sólo para subrayar la realización completa de la acción verbal, con un valor intensivo, convirtiéndose entonces el preverbio en un procedimiento que sólo acentúa el matiz aspectual ${ }^{29}$. Siendo así, la lectura $\pi \alpha \rho \alpha \rho \rho \alpha \psi \omega \delta o v ̃ v \tau o \varsigma$ podría ser perfectamente legítima.

Pero incluso priorizando la idea de 'exterioridad' como el único rasgo significativo del preverbio, en la medida en que la preposición $\pi \alpha \rho \alpha ́$ «señala una posición externa y cercana a un objeto que se considera limitado ${ }^{30}$, no

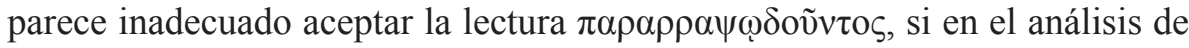
este pasaje se tienen en cuenta $\mathrm{y}$, al mismo tiempo, se combinan aspectos formales, también de contenido y de contexto.

Desde el punto de vista formal, el verbo $\dot{\rho} \alpha \omega \omega \delta \varepsilon \tilde{v} v$ compuesto con otros

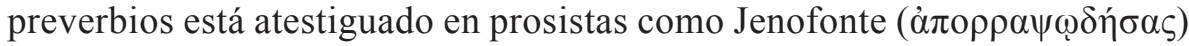
o Filóstrato $(\dot{\varepsilon} \pi \varepsilon \rho \rho \alpha \psi \omega ́ \delta \varepsilon 1, \dot{\varepsilon} \pi i \rho \rho \alpha \psi \omega \delta \eta \dot{\sigma} \sigma \alpha \nu \tau \sigma \zeta)^{31}$, y en el corpus lucianeo se encuentran las formas $\dot{\alpha} v \alpha \rho \rho \alpha \psi \omega \delta \dot{\sigma} \sigma \omega(\operatorname{ITr} 14)^{32}$ y $\dot{\varepsilon} \pi \iota \rho \rho \psi \omega \delta \tilde{\omega} v$ (Menip. 4) ${ }^{33}$, referidas siempre a Homero o a la poesía épica.

En cuanto a contenido, no debería omitirse que las palabras de Caronte son pronunciadas ahora a la luz del día, pero remiten a una escena acaecida en el tenebroso Aqueronte, donde la única realidad es, justamente, la irrealidad, la no vida, el fin de la existencia; y, por extensión, donde la única realidad es, desde

${ }^{28}$ Cf. Casevitz 1994; Mestre y Vintró 2010; Mestre 2010; Gómez y Mestre 2010.

${ }^{29}$ Cf. Rodríguez Alfageme 1988, pp. 57-59; Rodríguez Adrados 1992, p. 726.

${ }^{30}$ Rodríguez Alfageme 1988, p. 104.

${ }_{31}$ X., Cyr. III 3; Philostr., Her. 18; VS 614.

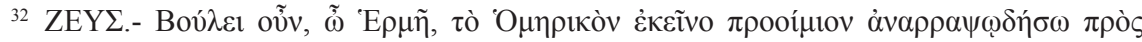

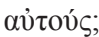

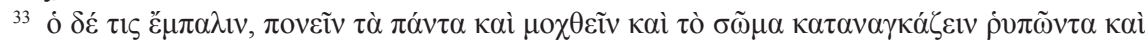

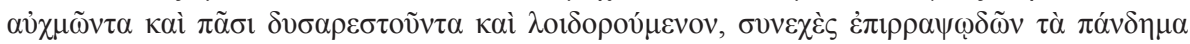

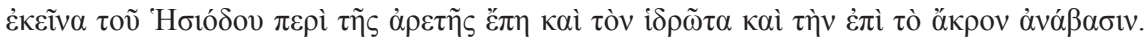


el punto de vista literario, la poesía mediatizada, tergiversada en su forma o en su contenido. Como tampoco es genuino cualquier canto ( $\hat{\phi} \delta \eta \dot{)}$ que se articula por similitud a otro, pero trueca $(\pi \alpha \rho \alpha-)$ forma o contenido; es decir, una parodia, según definición de Quintiliano (Inst. IX 2.35): incipit esse quodam modo $\pi \alpha \rho \omega \delta \eta$, quod nomen ductum a canticis ad aliorum similitudinem modulatis abusiue etiam in uersificationis ac sermonum imitatione seruatur ${ }^{34}$.

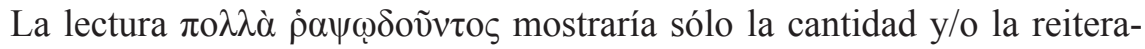
ción en el recitado que ejecuta Homero post mortem: incluso entonces el poeta era todavía capaz de recitar muchos versos y no cesaba de declamar. En cambio, la lectura $\pi \alpha \rho \alpha \rho \rho \alpha \psi \emptyset \delta o v ̃ v \tau o \varsigma$ quizás sirva mejor a las intenciones de Luciano, porque puede incorporar además alguna valoración cualitativa, específica, si se tiene en cuenta que el preverbio $\pi \alpha \rho \alpha-$, junto a la idea de paralelismo o proximidad, indica también — como explica Humbert«les mauvaises conditions dans lesquelles se passe l'action» ${ }^{35}$.

Hermes, como veíamos, cita a Homero para estructurar el marco del diálogo. En cambio, las citas de Caronte contribuyen, sobre todo, a dotar de contenido la conversación con el dios. Así, en una primera intervención recitando versos homéricos Caronte pregunta a Hermes a propósito de algunos individuos cuyas acciones transcurren ante su vista. El pasaje seleccionado por Luciano remite también a una atalaya de observación, al evocar hexámetros de la teichoskopía, con los que Príamo interroga a Helena mientras el rey y la espartana contemplan el asedio de Troya ${ }^{36}$ :

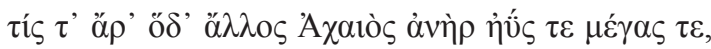

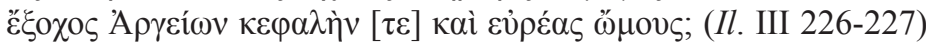

Y ambos versos son reformulados por Caronte en estos términos:

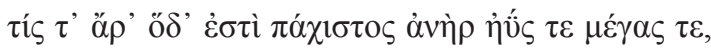

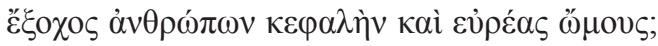

¿Quién es ese varón tan robusto, valeroso y alto, que entre los hombres descuella por su cabeza y anchos hombros? (Cont. 8).

${ }^{34}$ Para un análisis del significado general del término parodia y, en particular, aplicado a Luciano, véase Camerotto 1998, pp. 15-31.

${ }^{35}$ Humbert 1982, p. 340.

${ }^{36}$ Cf. Bouquiaux-Simon 1968, pp. 115-117. 
Se trata — como responde Helena a Príamo — del extraordinario ( $\pi \varepsilon \lambda \omega ́ \rho ı \varsigma)$

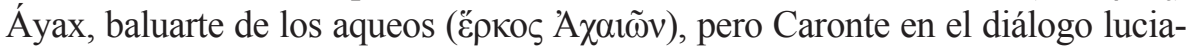
nesco está contemplando, aunque sea el mejor, sólo a un célebre atleta, Milón de Crotona cuyos grandes éxitos, alabados por Hermes, el barquero, por expe-

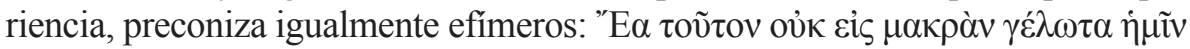

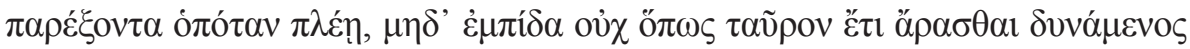
«iDéjalo! No a mucho tardar nos hará reír cuando emprenda su navegación y no sea capaz de levantar ya no un toro sino ni un mosquito» (Cont. 8$)^{37}$.

En esta primera cita el segundo y el tercer pie del hexámetro homérico

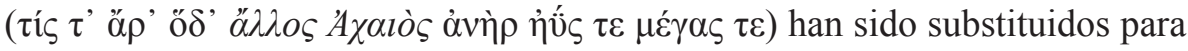
adecuarlos al contexto por una forma verbal y un nuevo adjetivo ( $\tau$ í $\tau^{\prime}$ ' $\alpha \rho^{\prime}$

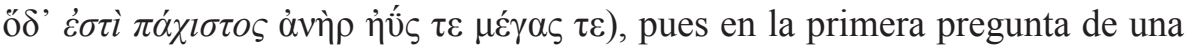
serie no encajaría el indefinido ö $\lambda \lambda \mathrm{o}$; hay, además, por parte de Luciano, una deliberada voluntad de desmitificar y rebajar la categoría heroica de la escena que ahora contemplan Caronte y Hermes, de modo que es del todo innecesario mencionar a los aqueos. Sin embargo, Caronte, fiel al lenguaje épico formular ${ }^{38}$, retoma otra vez - ahora parcialmente, sólo hasta la cesura heptemímeres - el verso inicial de ese mismo pasaje para su segunda pregunta y

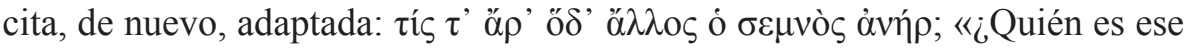
otro, el venerable varón?» (Cont. 9). En este caso Luciano sí mantiene el adjetivo indefinido $\alpha \ddot{\lambda} \lambda \mathrm{o}_{\mathrm{S}}$ y se limita a substituir una vez más el término

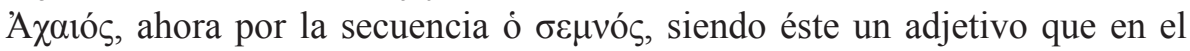
corpus homérico solamente aparece en los Himnos Homéricos ${ }^{39}$, y que Luciano suele emplear como término connotado para describir la altanería, la arrogancia o la falsa sabiduría ${ }^{40}$. Así, la dignidad que el término $\sigma \varepsilon \mu \nu$ ó $\varsigma$ confiere, correspondería, sin duda, a la categoría del individuo que divisan Caronte y Hermes desde su mirador, pues se trata nada menos que del fundador del imperio persa, Ciro el grande. Éste se dispone ya a «lanzarse sobre Lidia para derrocar a Creso y hacerse señor de todos sus dominios $\rangle^{41}$, pero, al igual

${ }^{37}$ Cf. Camerotto 1998, pp. 21-23.

${ }^{38}$ Luc., Cont. 19, donde Caronte se atreve también con los símiles homéricos cuando, para dar razón de la brevedad de la vida humana, la compara a simples burbujas de agua.

${ }^{39}$ Cf. h.Hom. I 1, 478, 486; IV 552; XXVIII 5.

${ }^{40}$ Como ilustran numerosos pasajes lucianeos, p. ej., DMort. XX 8; Symp. 28; Icar. 21; Vit. Auct. 2; Fug. 18; Merc. Cond. 25; Bis Acc. 33; Philops. 29.

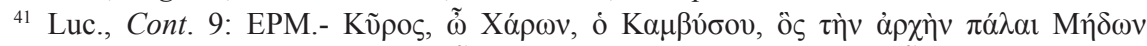

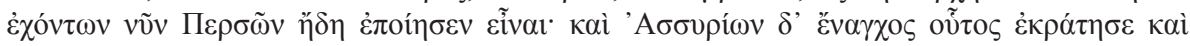


que Milón, también aparece ante sus observadores totalmente ajeno al destino que — según refiere Hermes- Cloto le tiene reservado a manos de la

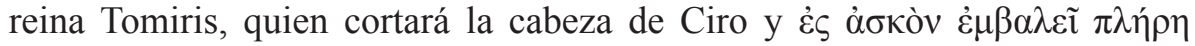

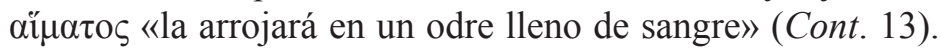

En este contexto antitético el canto de Caronte no podría ser un canto recto. Por el contrario, hay una utilización e intencionada inversión de los valores heroicos para ilustrar la inestabilidad de la perecedera existencia humana y, por ende, las extrañas preocupaciones de los infelices hombres. Caronte se asombra ante los inútiles asuntos mortales, que, a modo de síntesis, resume en poder de reyes ( $\beta \alpha \sigma i \lambda \varepsilon i \bar{\varsigma})$, ladrillos de oro ( $\pi \lambda i v v \theta o l \chi \rho v \sigma \alpha \tilde{i})$, ofren-

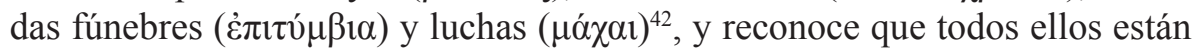
igualmente alentados por una muchedumbre (ö $\chi \lambda \mathrm{o}$ ) que en torno a los hombres revolotea. Integran esa multitud —como precisa Hermes-

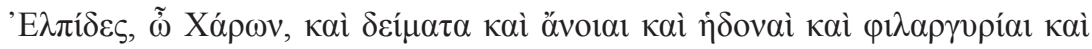

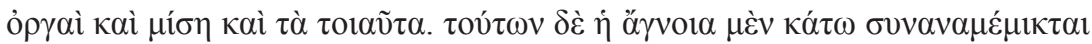

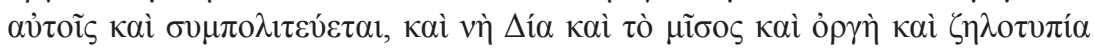

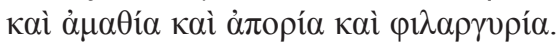

Vanas esperanzas, amigo Caronte, temores, insensateces, placeres, avaricia, pasiones, odios y otros vicios semejantes. Pero de entre ellos, la ignorancia es la que mejor se mezcla allí abajo con los hombres y gobierna sus acciones; y lo mismo sucede, por Zeus, con el odio, la pasión, la envidia, la ignorancia, la falta de recursos y la avaricia (Cont. 15).

Dicha inversión se sostiene también en la modificación que se produce en el contenido de la forma expresiva tomada como modelo; un cambio que halla su correlación en la transgresión del canto, en la parodia entendida de

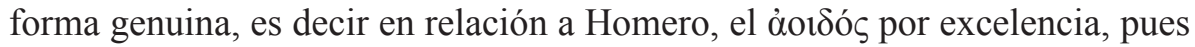
el término parodia, si se atiende al testimonio de Aristóteles ${ }^{43}$, se aplica, originariamente, a un poema narrativo, en metro y vocabulario épico, pero que trata un tema liviano, tal vez de puro entretenimiento, burlándose del contenido heroico de la poesía épica ${ }^{44}$, como Hermes reconoce explícitamente al

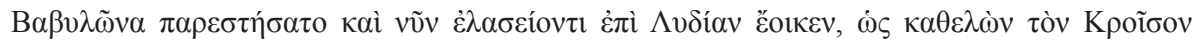

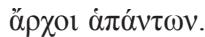

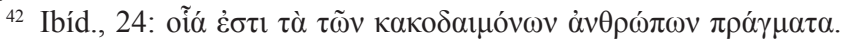

${ }^{43}$ Po. $1448^{a}$ 12-13.

${ }^{44}$ Cf. Gómez 1990, p. 17. 
afirmar: Eṽ $\gamma \varepsilon \pi \alpha \rho \emptyset \delta \varepsilon i \tilde{\varsigma}, \tilde{\omega}$ Xó $\rho \omega v$ «muy buena es tu parodia, Caronte» (Cont. 14).

En efecto, Caronte está parodiando a Homero, cuando hilvana diversos elementos formulares épicos para construir un hexámetro ${ }^{45}$ como habilidoso colofón a una nueva pregunta en la que Luciano sintetiza parte de la historia referida por Herodoto (I 204-214) sobre Polícrates:

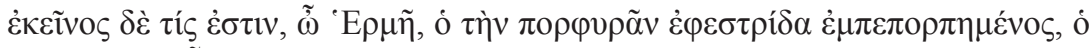

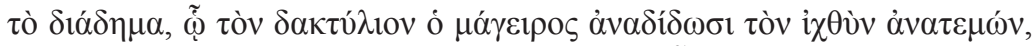

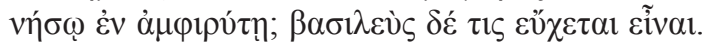

¿Y quién es aquél, Hermes, el que con hebillas tiene prendido el manto de púrpura, el de la diadema, a quien el cocinero al abrir el pez le devuelve el anillo,

en una isla azotada por las olas? Pues un rey se gloría de ser (Cont. 14).

Luciano contamina aquí doblemente forma y contenido. Transfiere la fe-

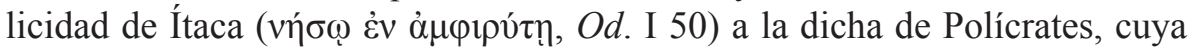
desgracia, descrita por Hermes en su respuesta, viene, no obstante, ya antici-

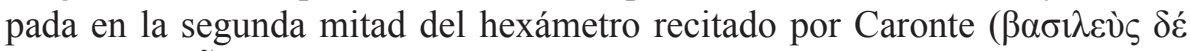

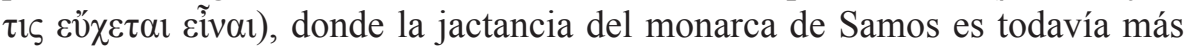

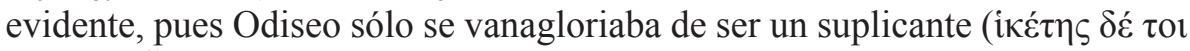

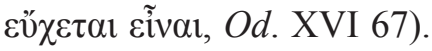

Todavía en otra ocasión Hermes reconoce categóricamente remiendos de

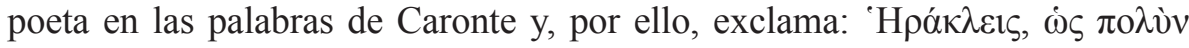

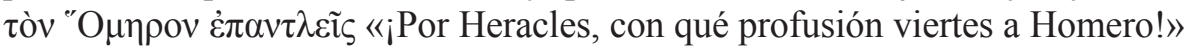
(Cont. 23). El término empleado ahora por el dios es غ̇ $\pi \alpha \nu \tau \lambda \varepsilon \tilde{\iota} \varsigma$, pertinente, sin duda, para describir tareas propias del ámbito náutico ${ }^{46}$, pero con el que Luciano, al mismo tiempo, denota algo de exceso en los versos del barquero, cuya dedicación a la poesía es, de este modo, identificada con un mero 'achicar' palabras ajenas, como si todavía, ahora en tierra, estuviera vaciando el barco que llenó Homero con su recitado, con su vómito. En cuanto a contenido, el asombro de Hermes se produce después de que Caronte acaba de arremeter otra vez contra la insensatez, y especialmente contra la vacuidad de las

${ }^{45}$ Cf. Bouquiaux-Simon 1968, pp. 348-349.

${ }^{46}$ Cf. Chantraine 1968, p. 93, s.u. óv $\tau \lambda$ os. 
honras fúnebres — que Luciano ridiculiza en otras obras ${ }^{47}$ —, todo ello debido siempre a la absoluta ignorancia de los mortales, quienes olvidan que

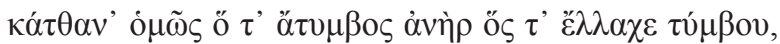

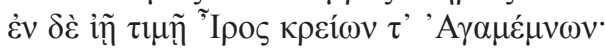

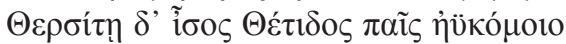

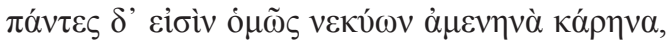

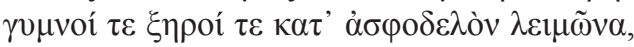

muere por igual el hombre sin tumba y quien sí la obtuvo en suerte,

y en idéntica honra están Iro y el poderoso Agamenón;

idéntico a Tersites es el hijo de Tetis, de hermosa cabellera,

todos son por igual frágiles calaveras de cadáveres,

desnudos y consumidos en un prado de asfódelos (Cont. 22).

Ese raudal de palabras que causa la exclamación de Hermes, corresponde a un verdadero pastiche - como señala Camerotto ${ }^{48}$ - , pues Luciano combina

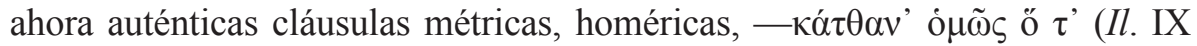

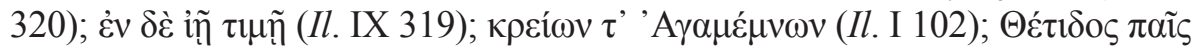

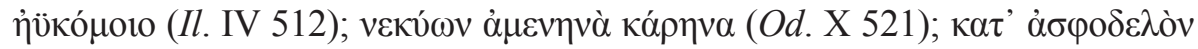

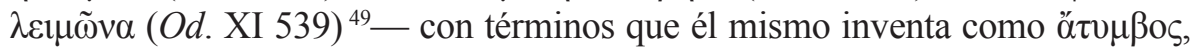
o bien adapta otras fórmulas épicas introduciendo en ellas vocablos inesperados, pero no exentos de una cierta ironía, como ocurre en el primer verso donde el genitivo $\tau u ́ \mu \beta o v$ es el régimen de la forma ع̌ $\lambda \lambda \alpha \chi \varepsilon$ : un verbo tal vez algo grandilocuente, desmesurado, en este contexto, puesto que los mortales suelen usarlo cuando quizás aspiran a obtener en suerte algo más o mejor que una tumba. En cualquier caso, en los hexámetros de Caronte prevalece, también de nuevo, la voluntad de degradar la condición heroica para ilustrar, como si fuera un espejo invertido, la mísera condición humana. Con tal intención, Caronte aúna al mendigo con el rey y el antihéroe con el héroe por excelencia, pero, al mismo tiempo, esa contaminación lo es también formal y de contenido al cruzarse en los versos del barquero motivos de la Ilíada -Agamenón, Aquiles o Tersites - y de la Odisea - Iro y los héroes en el Hades-.

Luciano, sin embargo, no imputa a Caronte esa capacidad de acertar en una contemplación e interpretación crítica de la vida terrenal, por ser un de-

${ }^{47}$ Como ejemplos sirvan Nec. 17; Luct. 22; DMort. XX, XXIX; Cat. 9. Sobre el lamento ritual en Luciano, cf. Evans 2009, pp. 65-78.

${ }^{48}$ Camerotto 1998, pp. 151-154.

${ }^{49}$ Cf. Bouquiaux-Simon 1968, pp. 343-344. 
clarado devoto de Cloto, su divinidad más querida ("A $\gamma \alpha \mu \alpha \imath \mathrm{K} \lambda \omega \theta$ oṽ $\varsigma$ $\gamma \varepsilon v v i \kappa \eta \tilde{\zeta} \cdot . ., \tilde{\omega} \beta \varepsilon \lambda \tau i ́ \sigma \tau \eta$, Cont. 14), sino por ser, ante todo, competente en tergiversar el canto, sea en forma, sea en contenido, para expresar su crítica reflexión sobre la vida de los hombres.

Por ello, Luciano sustenta y legitima la aptitud del barquero en el propio Homero, quien en vida conseguía incluso filosofar con su canto. Así lo explica el autor del Etymologicum Genuinum, cuando, al dar razón del término $\tilde{\alpha} \tau o \varsigma^{50}$, contrapone Ares, precisamente, a Oto y Efialtes, y postula — para

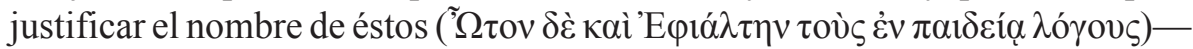

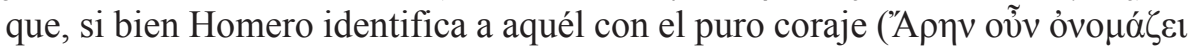

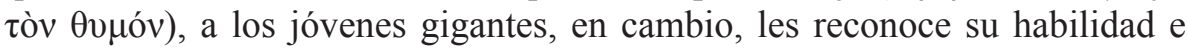

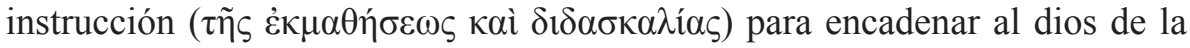
guerra y permitir a los hombres vivir en paz. Por ello afirma: $\beta \varepsilon ́ \lambda \tau \imath o v ~ \delta \grave{\varepsilon}$

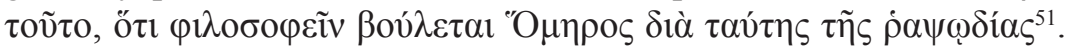

Sin embargo, después de muerto, Homero es sólo una sombra de sí mismo — como Aquiles, como Áyax, cuyas tumbas muestra Hermes a Caronte ${ }^{52}$ - y sólo alcanza a 'malcoser rapsodias' ( $\pi \alpha \rho \grave{\alpha}-\dot{\rho} \alpha \psi \omega \delta \varepsilon \tilde{v}$ ). Y éstas fueron, pues, los cantos que, como buen discípulo, oyó, aprendió y memorizó Caronte, sin duda poco útiles para él en el quehacer cotidiano del Averno, pero imprescindibles para poder expresarse durante su visita a la tierra, cuando, dejando de lado la práctica de la náutica, se puso él mismo, entre sonrisas y burlas ${ }^{53}$, también a filosofar sobre la existencia humana. Su reflexión, no obstante, le obliga a admitir que tan efímera es la condición de los mortales, incluso la de los héroes, como, perecederos por mudables, los cantos que debían garantizar a esos héroes gloria eterna, ya que los versos del poeta sólo son, en realidad, pura palabrería, si se atiende a

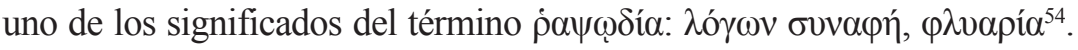

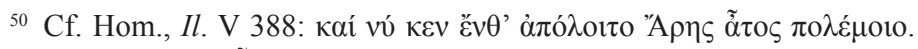

${ }^{51}$ Et.Gen. (s. u.) $\tilde{\alpha} \tau \mathrm{to}$.

${ }^{52}$ Cf. Luc., Cont. 23.

${ }^{53}$ Tí $\gamma \varepsilon \lambda \tilde{\alpha} \varsigma, \tilde{\omega}$ Xóp$\omega v$; «¿De qué te ríes, Caronte?» (Cont. 1), es la pregunta con que Hermes abre el diálogo, quizás porque el semblante del barquero suele ser siempre sombrío o porque de este modo Luciano da cuenta desde el inicio mismo de la pieza de cuál es su intención, pues el verbo $\gamma \varepsilon \lambda \alpha \dot{\omega} \omega$ o el substantivo $\gamma \varepsilon \dot{\lambda} \omega \varsigma$ y sus derivados son recurrentes a lo largo de la obra; cf. Cont. 1, 6, 8, 11, 13, 14, 16, 17, 21, 22.

${ }^{54}$ Cf. Et.Gud. (s. u.) $\dot{\rho} \alpha \psi \omega \delta i ́ \alpha$. 


\section{BIBLIOGRAFÍA}

Bompaire, J. 1958: Lucien écrivain. Imitation et création, París, Les Belles Lettres. Bompaire, J. 1993: Lucien. Oeuvres I. Opuscles 1-9, París, Les Belles Lettres.

Bompaire, J. 2008: Lucien. Oeuvres IV. Opuscles 26-29, París, Les Belles Lettres.

Bonazzi, M. 2010: «Luciano e lo scetticismo del suo tempo», en Mestre, F. y Gómez, P. (eds.), Lucian of Samosata. Greek Writer and Roman Citizen, Barcelona, Publicacions i Edicions de la Universitat de Barcelona, pp. 37-48.

Bouquiaux-Simon, O. 1968: Les lectures homériques de Lucien, Bruselas, Palais des Académies.

Brandão, J. L. 2001: A poética do Hipocentauro. Literatura, sociedade e discurso ficcional em Luciano de Samósata, Bello Horizonte, Editora da UFMG.

Branham, R. B. 1989: Unruly Eloquence. Lucian and the Comedy of Traditions, Cambridge-Londres, Harvard University Press.

Camerotto, A. 1998: La metamorfosi della parola. Studi sulla parodia in Luciano di Samosata, Pisa-Roma, Istituti editoriali e poligrafici internazionali.

Camerotto, A. 2009: Luciano di Samosata. Icaromenippo o l'uomo sopra le nuvole, Alessandria, Edizioni dell'Orso.

Casevitz, M. 1994: «La création verbal chez Lucien: le Lexiphanes, Lexiphane et Lucien», en Billault, A. (ed.), Lucien de Samosate, París, de Boccard, pp. 7786.

Chantraine, P. 1968: Dictionnaire étymologique de la langue grecque. I, París, Klincksieck.

Chantraine, P. 1974: Dictionnaire étymologique de la langue grecque. III, París, Klincksieck.

Decharneux, B. 2010: «Lucien doit-il être rangé dans la boîte des philosophes sceptiques ?», en Mestre, F. y Gómez, P. (eds.), Lucian of Samosata. Greek Writer and Roman Citizen, Barcelona, Publicacions i Edicions de la Universitat de Barcelona, pp. 63-71.

Díaz Lavado, J. M. 2010: Las citas de Homero en Plutarco, Zaragoza, Libros Pórtico.

Evans, S. 2009: «Ritual Lament in Lucian», en Bartley, A. (ed.), A Lucian for our Times, Cambridge, Cambridge Scholars Publishing, pp. 65-78.

Gil, L. 2004: Therapeia: la medicina popular en el mundo clásico, Madrid, Triacastela (Madrid, Guadarrama, 1969'1).

Gómez, P. 1990: «Parodia y parodiar en la Grecia antigua», EClás 98, pp. 7-25.

Gómez, P. 1994: «De Musa a Paideia: a propósito de la Vida de Luciano», en Actas del VIII Congreso Español de Estudios Clásicos, vol. II, Madrid, Ediciones Clásicas, pp. 205-211.

Gómez, P. y Mestre, F. 2006: «Luciano y la tradición de la mosca», en Calderón, E., Morales, A. y Valverde, M. (eds.), Koinòs Lógos. Homenaje al profesor José 
García López, vol. I, Murcia, Universidad de Murcia, Servicio de Publicaciones, pp. 353-364.

Gómez, P. y Mestre, F. 2010: «Traducir a Luciano», en Cañizares Ferriz, P. (ed.), Traducir a los clásicos, EClás. Anejo 1, pp. 117-128.

Hall, J. 1981: Lucian's Satire, Nueva York, Arno Press.

Helm, R. 1906: Lukian und Menipp, Leipzig (reimp. Hildesheim 1966), G. Olms.

Hemsterhuys, T. y Reitz, J. F. 1790: Luciani Samosatensis Opera Graece et Latine, vol. III, Deux-Ponts.

Humbert, J. 1982: Syntaxe Grecque, París, Klincksieck.

Jacobitz, C. 1836: Lucianus, vol. I, Leipzig, Teubner.

Jufresa, M., Mestre, F. y Gómez, P. 2000: Luciano. Obras III, Madrid, Alma Mater, Colección de autores griegos y latinos, Consejo Superior de Investigaciones Científicas.

Kindstrand, J. F. 1973: Homer in der Zweiten Sophistic, Uppsala, Almqvist \& Wiksell, «Acta Universitatis Upsaliensis - Studia Graeca Upsaliensia» 7.

Macleod, M. D. 1972: Luciani opera. Tomus I. Libelli 1-25, Oxford, Clarendon.

Mestre, F. 2004: «Refuting Homer in the Heroikos of Philostratus», en Aitken, E. B. y Maclean, J. K. B. (eds.), Philostratus's Heroikos. Religion and Cultural Identity in the Third Century C.E., Atlanta, Society of Biblical Literature, pp. 127-141.

Mestre, F. 2010: «Llucià i les variants de la llengua grega», en Borrell Vidal, E. y Gómez Cardó, P. (eds.), Artes and humanitatem. Mitologia, pensament, literatura, lingüística, filologia i tradició clàssica a l'entorn del món grec, vol. I, Barcelona, Secció Catalana de la SEEC, pp. 241-251.

Mestre, F. (e. p.): «Quelques idées sur la dramaturgie du dialogue chez Lucien» París, $B A G B$.

Mestre, F. y Vintró, E. 2010: «Lucien ne sait pas dire bonjour», en Mestre, F. y Gómez, P. (eds.), Lucian of Samosata. Greek Writer and Roman Citizen, Barcelona, Publicacions i Edicions de la Universitat de Barcelona, pp. 203-215.

Nesselrath, H. G. 1998: «Lucien et le Cynisne», AC 67, pp. 121-135.

Rodríguez Adrados, F. 1992: Nueva sintaxis del griego antiguo, Madrid, Gredos.

Rodríguez Alfageme, I. 1988: Nueva gramática griega, Madrid, Coloquio.

Fecha de recepción de la primera versión del artículo: 06/09/2010

Fecha de aceptación: 22/08/2011

Fecha de recepción de la versión definitiva: 16/09/2011 